\title{
(6) OPEN ACCESS \\ Procedural sedation in the emergency department by Dutch emergency physicians: a prospective multicentre observational study of 1711 adults
}

\author{
Gaël JP Smits, ${ }_{1}^{1}$ Maybritt I Kuypers, ${ }^{2}$ Lisette AA Mignot, ${ }^{3}$ Eef PJ Reijners, ${ }^{4}$ \\ Erick Oskam, ${ }^{5}$ Karen Van Doorn, ${ }^{6}$ Wendy AMH Thijssen, ${ }^{1}$ Erik HM Korsten ${ }^{7}$
}

\begin{abstract}
- Additional material is published online only. To view please visit the journal online (http://dx.doi.org/10.1136/ emermed-2016-205767).
\end{abstract}

For numbered affiliations see end of article.

\section{Correspondence to} Dr Gaël JP Smits, Emergency Department, Catharina Hospital, P.O. Box 1350, Eindhoven 5602 ZA, The Netherlands; gael. smits@catharinaziekenhuis.nl

Received 5 February 2016 Revised 27 September 2016 Accepted 2 October 2016

Published Online First

21 October 2016
CrossMark

To cite: Smits GJP, Kuypers MI, Mignot LAA et al. Emerg Med $\mathrm{J}$ 2017:34:237-242.

\section{ABSTRACT}

Objective To describe our experience performing ED procedural sedation in a country where emergency medicine (EM) is a relatively new specialty.

Methods This is a prospective observational study of adult patients undergoing procedural sedation by emergency physicians (EPs) or EM residents in eight hospitals in the Netherlands. Data were collected on a standardised form, including patient characteristics, sedative and analgesic used, procedural success, adverse events (classified according to World SIVA) and rescue interventions.

Results 1711 adult cases were included from 2006 to 2013. Propofol, midazolam and esketamine (S+ enantiomer of ketamine) were the most used sedatives $(63 \%, 29 \%$ and $8 \%)$. We had adverse event data on all patients. The overall adverse event rate was $11 \%$, mostly hypoxia or apnoea. There was no difference in adverse event rate between EPs and EM residents. However, there was a significantly higher success rate of the procedure when EPs did the procedural sedation (92\% vs $84 \%$ ). No moderate (unplanned hospital admission or escalation of care) or sentinel SIVA outcomes occurred (pulmonary aspiration syndrome, death or permanent neurological deficit).

Conclusion Adverse events during procedural sedation occurred in $11 \%$ of patients. There were no moderate or sentinel outcomes. All events could be managed by the sedating physician. In a country where EM is a relatively new specialty, procedural sedation appears to be safe when performed by EPs or trained EM residents and has comparable adverse event rates to international studies.

\section{INTRODUCTION}

Procedural sedation and analgesia (PSA) is an essential technique that enables emergency physicians (EPs) to perform painful procedures in a humane and timely manner within the ED. However, without proper physician and nurse training, vital signs monitoring and quality assurance, sedation can lead to serious adverse events. In 1995, Quine reported a mortality of 1 in 2000 sedated patients for gastroscopy in the UK and found that only $40 \%$ of patients had oxygen saturation monitoring during the procedure. ${ }^{1}$ Since then multiple studies have shown that procedural sedation is safe, and deaths are very infrequent when it is done in concordance with current procedural sedation guidelines. ${ }^{2-4}$

The emergency medicine (EM) training programme in the Netherlands was officially recognised by the Medical Specialist Registration

\section{Key messages}

What is already known on this subject?

- Procedural sedation is safe when performed by emergency physicians.

- The use of propofol for ED sedation by emergency medicine doctors is not well accepted by some non-emergency medicine specialties in some countries.

What this study adds?

- Procedural sedation is safe in the hands of emergency physicians and residents in a country where emergency medicine is a relatively new specialty.

- Our findings suggest that the safety profile of propofol is similar to that of midazolam. However, sedation was more often successful with the use of propofol.

Committee of the Royal Dutch Society for Medicine in 2008 and as such is still a very young specialty in the Netherlands. The first 3-year EM training programmes in the Netherlands started in 2000 in four hospitals spread over the country. Prior to this, and to some extent till today, the EDs were mostly staffed by recent medical school graduates, often working only with distant supervision by telephone by a non-EM specialist. ${ }^{5}$ Most internists, orthopaedists, surgeons and non-ED residents are not trained in PSA and rely on the anaesthesiologists who are usually not readily available in the ED and are not comfortable with sedating nonfasted patients. ${ }^{6}$ As a result, procedures are either performed in the ED without adequate analgesia and sedation or have to go to the operating theatre, which leads to prolonged waiting times and increased expenditure. ${ }^{7}$

Two of the early adaptors of Dutch ED training programmes (the OLVG and Albert Schweitzer hospital) invited US trained physicians to serve as residency directors and help train their residents. During this time procedural sedation was introduced. ${ }^{6}$ In another hospital (St. Elisabeth Hospital, Tilburg), PSA was introduced to the EM physicians by an anaesthesiologist. Since then its use has spread. In 2012, the Netherlands Society of Emergency Physicians (NSEP) launched a national EM PSA course for EPs, following the guidelines of the Dutch Institute for Healthcare Improvement. ${ }^{4}$ 
Aside from contributing to the world's literature on safety of PSA by EPs, it is important to assess its safety in a country where EM is a relatively new specialty. We included all used sedatives to reflect the practice in our country.

The aim of this multicentre study was to assess the safety of ED procedural sedation by Dutch EM physicians and EM residents.

\section{METHODS}

\section{Study design and setting}

This is a prospective observational study of adult patients undergoing procedural sedation by EPs or EM residents in eight hospitals in the Netherlands (seven community hospitals (of which six are EM teaching hospitals) and one academic medical centre) from 2006 to 2013. Not all hospitals contributed data for the whole period (2006-2013) because PSA was not introduced at the same time. The annual census of these hospitals ranged from 14.490 to $41.586 \mathrm{ED}$ visits. The study was approved by the nationally recognised Institutional Review Board of the Catharina hospital Eindhoven and this decision was adopted by the other participating centres.

\section{Selection of participants}

Patients aged 17 and older were included if they received PSA in the ED by a qualified EP consultant or EM resident. Dutch EM residents all have airway management training in their first months of training and have to perform supervised PSAs until deemed competent to perform it unsupervised. Only American Society of Anesthesiologists (ASA) class I-III patients were eligible for PSA by non-anaesthesiologists in keeping with the 1998 national consensus guidelines. ${ }^{8}$ Patients were excluded if sedation was needed to treat agitation or psychosis or if sedation was needed for intubation or mechanical ventilation. Fasting state was not an exclusion criterion.

\section{Interventions}

A preprocedural screening was performed using a standardised PSA registration form. Information recorded included ASA classification, medical history, allergies, height and weight, expected airway difficulties and fasting state. Vitals signs were measured at regular intervals, during and after the procedure, until the patient was fully awake. The measurements included BP, RR, pulse oximetry and HR. ECG monitoring was included in most patients as well. Except for one hospital, end-tidal $\mathrm{CO}_{2}$ monitoring was not used since it has only been recently introduced in the Dutch setting. Depth of sedation was registered using ASA levels of sedation for non-esketamine sedations. One hospital used Ramsay scale instead of ASA. ${ }^{9}$ When esketamine (the $\mathrm{S}+$ enantiomer of ketamine) was used, the dissociative state was registered (yes/no). Airway equipment was available in the room, and full resuscitation equipment readily available in the department. The patients received a sedative and analgesic depending on the local ED protocol.

After the PSA, the physicians registered the deepest level of sedation, amnesia, pain ratings with the verbal numerical rating scale (VNRS-11;0=no pain to $10=$ worst imaginable pain), ${ }^{10}$ duration of PSA (from administration of the sedative until the discharge criteria were met) and successful completion of the procedure for which the PSA was required. The discharge criteria were level of consciousness as before sedation, able to eat and drink, no nausea, pain well under control, vital signs stable (breathing, circulation), and a minimum of 2 hours after administration of a reversal agent.

\section{Methods and measurements}

Data were registered using a procedural sedation form, based on the template of the Netherlands Society of Emergency Physicians (see online supplementary file 1). Additionally, all participating centres were queried for events related to procedural sedation in the ED through their hospital adverse incidents databases.

\section{Outcomes}

The primary outcome was the number of adverse events, defined as: airway obstruction, apnoea ( $>20 \mathrm{~s}$ ), hypoxia (oxygen saturation $<90 \%$ for $>60$ s), hypotension (systolic BP $<90 \mathrm{~mm} \mathrm{Hg}$ ), bradycardia (<50/min), agitation, aspiration, hospital admission due to PSA, or other.

To classify the interventions and outcomes after an adverse event, the World SIVA adverse sedation reporting tool was applied in retrospect. ${ }^{11}$

\section{SIVA interventions}

These are classified as minimal (no intervention, additional sedatives, antiemetics or antihistamines), minor (airway repositioning, tactile stimulation, supplemental oxygen or antisialagogue), moderate (bag valve mask ventilation, laryngeal mask, oral/nasal airway, continuous positive airway pressure, reversal agents, rapid intravenous fluids or intravenous anticonvulsant) and sentinel (cardiopulmonary resuscitation, tracheal intubation, neuromuscular block, pressor/epinephrine or atropine to treat bradycardia).

\section{SIVA outcomes}

These are classified as minimal (no adverse outcome), moderate (unplanned hospital admission or escalation of care) and sentinel (pulmonary aspiration syndrome, death or permanent neurological deficit).

Secondary outcomes were success of the procedure and amnesia.

Post hoc, we investigated the influence of seniority (EP vs EM resident) on adverse events rate, procedural success rate and choice of sedative.

\section{Analysis}

Data were analysed with SPSS V.19. Continuous variables were presented as means (95\% CIs) or medians (IQR; min-max) depending on normal distribution of the data. Categorical variables were presented as percentages. We used the modified Wald method (Agresti and Coull) to calculate 95\% CI of proportions, and the Wilson method (without continuity correction) for $95 \%$ CI for difference between proportions. A Kruskal-Wallis $\mathrm{H}$ test, followed by a Mann-Whitney U test with Bonferroni correction, was used for testing continuous variables per sedative (duration of sedation). A $\chi^{2}$ test was used for significance of categorical data (adverse events, success of the procedure, amnesia, level of training, age groups, oxygen use, level of sedation). A Mann-Whitney $\mathrm{U}$ test was used for calculating significance for sedative dosing in age groups and level of training. A logistic analysis was used for testing association between patient age and adverse events. A p value less than 0.05 was considered statistically significant.

\section{RESULTS}

\section{Characteristics of study subjects}

The analysis included 1711 patients (17 patients were excluded due to unrecorded patient age). Patient characteristics are described in table 1 . The median age was 59 years (min-max 17-100 years), with $41.8 \%$ aged 65 and older. More than half had an ASA class of I. 
Table 1 Characteristics of patients undergoing procedural sedation in the ED $(n=1711)$

\begin{tabular}{lll}
\hline & $\mathbf{n}^{*}$ & \\
\hline Median age, years (IQR) & 1711 & $59(41-77)$ \\
Men, \% & 1709 & 46.0 \\
Median body weight, kg (IQR) & 1602 & $75(65.5-84.5)$ \\
ASA class, \% & 1699 & 53.3 \\
I & & 40.0 \\
II & & 6.7 \\
III & 1311 & 19.0 \\
Fasting in hours, \% & 44.4 \\
0-3 & & 36.6 \\
3-6 & & \\
$>6$ & & \\
\hline * Due to missing data, this is the total number of cases included in the analysis of \\
this variable. \\
ASA, American Society of Anesthesiologists.
\end{tabular}

\section{Main results}

The most frequent indications for PSA were dislocations of the hip and shoulder $(29.2 \%$ and $26.1 \%$; online supplementary table S1).

Propofol and midazolam were the most commonly used sedatives with an average dose of 1.1 and $0.06 \mathrm{mg} / \mathrm{kg}$, respectively (table 2). In the majority of the non-esketamine cases, an opioid was added before giving the sedative (85.3\%).

Propofol was associated with a significant shorter duration of sedation $(\mathrm{p}<0.001)$ when compared with esketamine or midazolam (table 2$)$.

ASA sedation depth was registered in only 985 of 1315 patients (table 4), with $36.7 \%$ being deeply sedated or higher. In the one hospital that used the Ramsay sedation scale, sedation depth was registered in 206 of 267 cases, with 38.9\% having a scale of 4 or 5 (brisk or sluggish response to a light glabellar tap or to verbal stimulus) and no one with a scale of 6 (no response). Dissociation scoring was registered in 71 of 129 esketamine cases with $77.5 \%$ of 71 patients being dissociated.

\section{Adverse events}

There were a total of 194 adverse events involving 181 of 1711 patients $(10.6 \%$; table 3$)$, most frequently hypoxia $(4.0 \%)$ and apnoea $(2.9 \%)$. Bag valve mask ventilation and airway repositioning were performed in $2.6 \%$ and $2.0 \%$, respectively. All events were successfully treated by the sedating physician. There were no sentinel interventions, moderate or sentinel outcomes as a result of the PSA. The majority of patients (74.6\% of 1458) received supplemental oxygen, and there was however no significant difference in adverse events (supplemental oxygen $10.1 \%$, no oxygen $13.8 \%$; difference $3.7 \%$ (95\% CI $0.0 \%$ to $7.9 \%) ; \mathrm{p}=0.051)$.

There was no significant difference in percentage of adverse events between propofol, midazolam and esketamine $(p=0.88$; table 2). There was, however, an increasing frequency of adverse events with increasing age $(\mathrm{p}<0.001$; figure 1$)$ despite statistically significant lower total sedative dosing in patients aged 65 and over (median dose $\mathrm{mg} / \mathrm{kg}$ (IQR) propofol $0.9(0.6-1.3)$ vs $1.3(0.8-1.8) \mathrm{p}<0.001$; midazolam $0.04(0.03-0.06)$ vs 0.05 $(0.03-0.08) \mathrm{p}=0.025$; esketamine $0.4(0.3-0.5)$ vs $0.5(0.4-0.6)$ $\mathrm{p}<0.001)$.

Propofol had a higher adverse event rate in patients aged 65 and over $(17.0 \%$ vs $7.1 \%$; difference $9.9 \%$; $95 \%$ CI $5.9 \%$ to $14.3 \% ; \mathrm{p}<0.001)$. This was not significant for midazolam (13.0\% vs $7.9 \%$; difference $5.1 \%$; $95 \%$ CI $-0.5 \%$ to $10.4 \%$; $\mathrm{p}=0.07)$.

No additional events or incidents were found in the hospitals' adverse incident reporting systems.

\section{Success of procedure and amnesia}

The procedures could be successfully completed with PSA in $90.1 \%$ of cases.

Propofol was associated with a significant higher procedural success rate than midazolam $(93.1 \%$ vs $84.1 \%$; difference $9.1 \% ; 95 \%$ CI $5.7 \%$ to $12.9 \% ; \mathrm{p}<0.001)$ and esketamine (88\%; difference $5.2 \%$; $95 \%$ CI $0.2 \%$ to $12.1 \%$; $<<0.001$; table 2). There was no statistically significant association between dosage and procedural success rate.

In $83.4 \%$ of patients there was amnesia to the procedure (table 2). With esketamine, there was significantly more amnesia than with midazolam (difference $11.7 \%$; 95\% CI $0.6 \%$ to $20.0 \% ; \mathrm{p}=0.38$ ), but not compared with propofol (difference $6.6 \% ; 95 \% \mathrm{CI}-3.5 \%$ to $12.5 \%$; $\mathrm{p}=0.17$ ).

As expected, there was an increase of amnesia with increasing sedation levels (table 4). Minimal and moderate levels had significantly less amnesia than deep or general anaesthesia $(75.8 \%$

Table 2 Sedatives used in patients undergoing procedural sedation in the ED $\left(n=1711^{*}\right)$

\begin{tabular}{|c|c|c|c|c|c|c|}
\hline & \multicolumn{2}{|c|}{$\begin{array}{l}\text { Propofol } \\
n=1074\end{array}$} & \multicolumn{2}{|c|}{$\begin{array}{l}\text { Midazolam } \\
n=499\end{array}$} & \multicolumn{2}{|c|}{$\begin{array}{l}\text { Esketamine } \\
n=129\end{array}$} \\
\hline & \multicolumn{2}{|l|}{ nt } & \multicolumn{2}{|l|}{ nt } & \multicolumn{2}{|l|}{ nt } \\
\hline Median age (IQR) & 1074 & $55.5(38-73)$ & 499 & $69(54-84)$ & 129 & $48(32.5-63.5)$ \\
\hline Median total dose, mg/kg (IQR) & 942 & $1.1(0.7-1.6)$ & 413 & $0.06(0.04-0.08)$ & 108 & $0.5(0.3-0.6)$ \\
\hline Median sedation duration, minutes (IQR) & 631 & $15(11-19)$ & 175 & $25(12.5-37.5)$ & 40 & $25(16-34)$ \\
\hline ASA sedation deep or higher $¥, \%(95 \% \mathrm{CI})$ & 691 & 43.1 (39.5 to 46.9$)$ & 288 & $21.5(17.2$ to 26.6$)$ & 71 & $77.5(66.5$ to 85.6$) \ddagger$ \\
\hline Opioid coanalgesia, \% (95\% Cl) & 1074 & 84.2 (81.9 to 86.2$)$ & 499 & 87.6 (84.4 to 90.2$)$ & 129 & $12.4(7.8$ to 19.2$)$ \\
\hline Esketamine coanalgesia, \% (95\% Cl) & 1074 & $2.0(1.4$ to 3.1$)$ & 499 & $0(0$ to 0.8$)$ & 129 & $0(0$ to 3.9$)$ \\
\hline Adverse events, \% $(95 \% \mathrm{Cl})$ & 1074 & 10.7 (9.0 to 12.7$)$ & 499 & 10.8 (8.4 to 13.9$)$ & 129 & $9.3(5.3$ to 15.7$)$ \\
\hline Amnesia, \% (95\% Cl) & 677 & 83.9 (80.9 to 86.5$)$ & 179 & 78.8 (72.2 to 84.2$)$ & 63 & 90.5 (80.4 to 95.9$)$ \\
\hline Success of procedure, $\%(95 \% \mathrm{Cl})$ & 1051 & 93.1 (91.5 to 94.5$)$ & 483 & 84.1 (80.5 to 87.1$)$ & 125 & 88.0 (81.0 to 92.7$)$ \\
\hline
\end{tabular}


Table 3 Adverse events with their interventions in patients undergoing procedural sedation in the $E D(n=1711)$

\begin{tabular}{|c|c|}
\hline & $\begin{array}{l}\text { Adverse events, } \\
\text { n (\%) }\end{array}$ \\
\hline \multicolumn{2}{|l|}{ Minimal intervention* } \\
\hline Agitation & $6(0.4)$ \\
\hline Emesis & $5(0.3)$ \\
\hline Emergence phenomena & $3(0.2)$ \\
\hline Hypotension-no intervention & $7(0.4)$ \\
\hline Hypoxia-no intervention & $1(0.1)$ \\
\hline Tachycardia & $1(0.1)$ \\
\hline $\begin{array}{l}\text { Other: subcutaneous injection of sedative }(n=1) \text {, } \\
\text { unknown }(n=1)\end{array}$ & $2(0.1)$ \\
\hline Total minimal intervention & $25(1.5)$ \\
\hline \multicolumn{2}{|l|}{ Minor intervention* } \\
\hline Airway obstruction-stimulate & $3(0.2)$ \\
\hline Airway obstruction-airway repositioning & $27(1.6)$ \\
\hline Apnoea-stimulate & $23(1.3)$ \\
\hline Hypoxia_-stimulate & $13(0.8)$ \\
\hline Hypoxia_-airway repositioning & $8(0.5)$ \\
\hline Hypoxia-oxygen administration & $25(1.5)$ \\
\hline Total minor intervention & $99(5.8)$ \\
\hline \multicolumn{2}{|l|}{ Moderate interventions* } \\
\hline Airway obstruction-oral airway insertion & $2(0.1)$ \\
\hline Apnoea-bag valve mask ventilation & $25(1.5)$ \\
\hline Apnoea-reversal agent administration & $2(0.1)$ \\
\hline Hypotension-fluid bolus & $20(1.2)$ \\
\hline Hypoxia-bag valve mask ventilation & $19(1.1)$ \\
\hline Hypoxia—reversal agent administration & $2(0.1)$ \\
\hline Total moderate intervention & $70(4.1)$ \\
\hline Sentinel interventions & $0(0)$ \\
\hline Total number of adverse events & $194(11.3)$ \\
\hline Total number of cases with adverse eventst & $181(10.6)$ \\
\hline
\end{tabular}

vs $92.9 \%$; difference $17.1 \%$; $95 \%$ CI $12.1 \%$ to $21.9 \%$; $\mathrm{p}<0001)$.

\section{Level of training}

The majority of patients (79.7\%) were sedated by an EP, and the remainder by an EM resident.

EPs used propofol and esketamine more frequently than EM residents (table 5). The doses of the sedatives in $\mathrm{mg} / \mathrm{kg}$ were the same. The percentage of adverse events was the same for EP

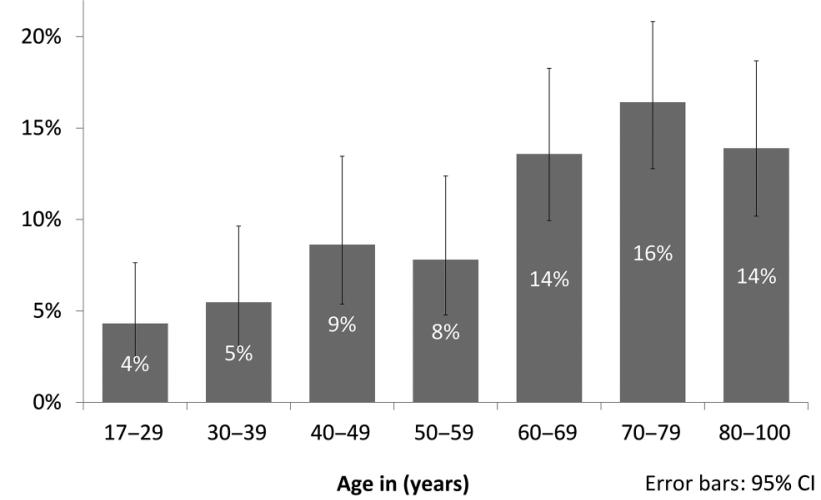

Figure 1 Patients with adverse events per age group during procedural sedation in the ED $(n=1711)$.

and EM residents. However, EPs had a significantly higher overall success rate of the procedure than residents (table 5).

\section{DISCUSSION}

Adverse events rate

In this multicentre study of 1711 adults undergoing procedural sedation by EPs, we found adverse events in 10.6\% of patients. There were no sentinel outcomes. There was no statistical difference in adverse event rate between propofol, midazolam and esketamine. In other studies, the adverse event rate for propofol versus midazolam was also similar or even lower, ${ }^{2}$ 12-15 refuting the notion that propofol is not suitable for use by non-anaesthesiologists.

The adverse event rate in our Dutch multicentre study is comparable with the rate in other international studies $(3.5 \%-$

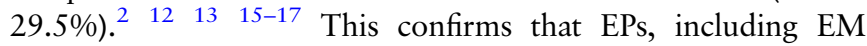
residents, can safely perform PSA in a country with a relatively new EM training programme. We found no difference in adverse event rate between EPs and EM residents. Similar rate of adverse events in EM residents suggests that this was a safe practice. Since 2015 PSA training is part of the core curriculum of the EM training programme.

Increasing age was significantly associated with increasing adverse events in our study, despite the fact that they received significantly lower sedative doses. Increased adverse event rate with age is found in some studies, but not all. ${ }^{13} 18$

\section{Success of the procedure}

Our overall procedural success rate of $90 \%$ is not as high as other studies (95\%-96\%); however, this may be partly due to a higher rate of hip reductions in our study, a procedure known

Table 4 Sedation level ${ }^{*}$ and amnesia in patients undergoing procedural sedation in the ED $(n=1711)$

\begin{tabular}{|c|c|c|c|c|}
\hline \multirow[b]{2}{*}{ ASA levels of sedation } & \multicolumn{2}{|c|}{ Total } & \multicolumn{2}{|c|}{ Amnesia } \\
\hline & nt & $\%(95 \% \mathrm{Cl})$ & nt & $\%(95 \% \mathrm{Cl})$ \\
\hline Minimal & 158 & $16.0(13.9$ to 18.5$)$ & 105 & 47.6 (38.3 to 57.1$)$ \\
\hline Moderate & 465 & $47.2(44.1$ to 50.3$)$ & 341 & 84.5 (80.2 to 87.9$)$ \\
\hline Deep & 343 & 34.8 (31.9 to 37.9 ) & 293 & 92.8 (89.3 to 95.3$)$ \\
\hline General anaesthesia & 19 & $1.9(1.2$ to 3.0$)$ & 17 & 94.1 (73.0 to 99.0$)$ \\
\hline Total & 985 & 100 & 756 & 82.8 (80.0 to 85.3 ) \\
\hline
\end{tabular}

*Patients with missing data, Ramsay sedation scale or ketamine dissociation scale $(n=49)$ not included in this table.

tDue to missing data, this is the total number of cases included in analysis of this variable (denominator).

ASA, American Society of Anesthesiologists. 
Table 5 Level of training and outcomes in patients undergoing procedural sedation in the ED $(n=1711)$

\begin{tabular}{|c|c|c|c|c|c|}
\hline & \multicolumn{2}{|c|}{$\begin{array}{l}E P, n=1364 \\
n *\end{array}$} & \multicolumn{3}{|c|}{ EM resident, $n=347$} \\
\hline Propofol used, n (\%) & 887 & $887(65.0)$ & 187 & $187(53.9)$ & \\
\hline Median dose, mg/kg (IQR) & 818 & $1.1(0.7-1.6)$ & 124 & $1.0(0.5-1.5)$ & $p=0.35$ \\
\hline Success of procedure, $\%(95 \% \mathrm{Cl})$ & 866 & 94.3 (92.6 to 95.7 ) & 185 & 87.6 (82.0 to 91.6$)$ & $\mathrm{p}<0.001$ \\
\hline Midazolam used, n (\%) & 345 & $345(25.3)$ & 154 & $154(44.4)$ & \\
\hline Median dose, mg/kg (IQR) & 275 & $0.04(0.02-0.06)$ & 138 & $0.05(0.03-0.07)$ & $p=0.16$ \\
\hline Success of procedure, $\%(95 \% \mathrm{Cl})$ & 337 & 86.1 (81.9 to 89.4$)$ & 146 & 79.5 (72.1 to 85.3$)$ & $p=0.07$ \\
\hline Esketamine used, n (\%) & 124 & $124(9.1)$ & 5 & $5(1.4)$ & \\
\hline Median dose, mg/kg (IQR) & 107 & $0.46(0.3-0.6)$ & & $\dagger$ & \\
\hline Success of procedure, $\%(95 \% \mathrm{Cl})$ & 120 & 87.5 (80.3 to 92.4$)$ & & $\dagger$ & \\
\hline Other sedatives used, n (\%) & 8 & $8(0.6)$ & 1 & $1(0.3)$ & \\
\hline Success of procedure, $\%(95 \% \mathrm{Cl})$ & 1331 & 91.7 (90.1 to 93.0$)$ & 337 & 84.0 (79.7 to 87.5$)$ & $p<0.001$ \\
\hline Adverse events, $\%$ of cases $(95 \% \mathrm{Cl})$ & 347 & 10.5 (9.0 to 12.2$)$ & 1364 & $11.0(8.1$ to 14.7$)$ & $p=0.8$ \\
\hline
\end{tabular}

to have higher failure rates. ${ }^{2} 19$ Excluding all hip reductions in our study would increase the success rate to 93\%. Relative inexperience with the procedure itself for which PSA was indicated might also have contributed.

We found a $7.7 \%$ absolute difference in success rate in favour of EPs compared with EM residents. This is not explained by sedative dosing, since this was similar in EPs and EM residents. Possibly when PSAs were done by EM residents they were assisted by a junior doctor (EM or specialty resident) to perform the indicated procedure.

In our study, propofol was associated with better procedural success rates than midazolam (even when corrected for the higher number of hip reductions in the midazolam group), which is similar to a study where 316 sedations in the ED were retrospectively analysed. ${ }^{14}$ In our study, patients receiving propofol had deeper levels of sedation than with midazolam, which may further explain its higher success rate.

Prudent midazolam dosing in our study $(0.06 \mathrm{mg} / \mathrm{kg}) \mathrm{might}$ have contributed to the lower success rates, as reported by Hohl et al. ${ }^{20}$ Total dose of midazolam varies in the ED literature, from around 0.05 to $1.0 \mathrm{mg} / \mathrm{kg}$ or more. ${ }^{15} 21-23$ It is possible that the relatively high median age in our midazolam cohort (69 years) is a reason why such low doses were used.

Propofol and esketamine in our study had similar success rates, in contrary to an observational study from Australia, where ketamine had the highest rate. ${ }^{19}$

\section{Amnesia}

We found amnesia in $83 \%$ of patients, less than we would have expected. Likely this is due to the lower sedation levels in our cohort (ASA sedation level minimal 16\%, moderate 47\%), as we found lower sedation levels to be associated with less amnesia.

\section{Limitations}

We collected data from multiple centres, using mainly paper forms, which led to missing data for some variables such as ASA classification, body weight, sedation depth, success of procedure and amnesia. We however included all patients with missing data, except when the patients' age could not be found (to not accidentally include paediatric patients in our cohort).
During the study period, there was no mandatory registration of PSA by the NSEP. It is, therefore, possible that not all cases were registered. To find any occult serious adverse events, we, therefore, queried the hospitals' patient safety incident reporting databases, which showed no additional adverse events.

The variable amnesia was registered in only 54\% of cases. Potentially the sedating doctor could have omitted to register amnesia if the patient was not amnestic. However, our amnesia rate of $83 \%$ is rather on the low side when compared with the literature. For example, recall of the procedure was found in $7.4 \%$ of 121 ER patients using propofol or midazolam ${ }^{24}$ and $10 \%$ of 271 patients sedated with propofol or propofol/ketamine. ${ }^{17}$

In one hospital, sedation depth was not registered with ASA sedation levels, but with the Ramsey sedation score, which makes comparison more difficult. Furthermore, in the other hospitals ASA levels were only registered in $75 \%$ of patients. This reduced the number of patients in our analysis for sedation levels and has the potential to skew the results.

Since uniform reporting of adverse events only has been proposed in $2012,{ }^{9}$ we only could retrospectively apply the World SIVA reporting tool. We applied this tool to the interventions needed and outcomes, not the adverse events themselves, since the tool used different cut-offs than ours.

\section{CONCLUSION}

In conclusion, procedural sedation-in a country where EM is a relatively new specialty - appears safe when performed by EPs and trained EM residents and has comparable adverse event rates as international studies, and resulted in no sentinel outcomes.

\section{Author affiliations}

${ }^{1}$ Emergency Department, Catharina Hospital, Eindhoven, The Netherlands 2Emergency Department, Tergooi Ziekenhuis, Hilversum, The Netherlands ${ }^{3}$ Emergency Department, Maxima Medical Centre, Veldhoven, The Netherlands ${ }^{4}$ Emergency Department, St. Elisabeth Hospital, Tilburg, The Netherlands ${ }^{5}$ Emergency Department, Albert Schweitzer Hospital, Dordrecht, The Netherlands ${ }^{6}$ Emergency Department, Medisch Centrum Haaglanden, The Hague, The Netherlands

${ }^{7}$ Department of Anaesthesiology, Intensive Care and Pain Catharina Hospital, Eindhoven, The Netherlands

Acknowledgements We thank the following hospitals for participating in the study: Catharina Hospital, Eindhoven; Maxima Medical Centre, Veldhoven; Meander 
Hospital, Amersfoort, St. Elisabeth Hospital, Tilburg; Albert Schweitzer Hospital, Dordrecht/Zwijndrecht; Haga Hospital, Den Haag; Westfriesgasthuis, Hoorn and Radboud University Nijmegen Medical Centre, Nijmegen. We thank Saskia Houterman, PhD, epidemiologist, for reviewing the manuscript and statistical analysis; RTC Welsing, MD, emergency physician KNMG, Meander Medical Centre, Amersfoort; ATW Wei, MD, emergency consultant KNMG, Radboud University Medical Centre for providing data and Francis Mencl, MD, MS, FACEP, FAAEM, Summa Akron City hospital, Northeastern Ohio Medical University for reviewing the manuscript.

Contributors GJPS and MIK conceived the study and GJPS undertook recruitment of participating centres. GJPS, MIK, LAAM, EPJR, EO, KVD and WAMHT acquired the data. GJPS managed the data. MIK, WAMHT and EHMK helped with analysing and interpreting the data. GJPS drafted the manuscript. All authors contributed substantially to its revisions. GJPS takes responsibility for the paper as a whole.

Competing interests None.

Ethics approval Catharina Hospital Institutional Review Board.

Provenance and peer review Not commissioned; externally peer reviewed.

Data sharing statement We also collected the variable 'difficulty of the procedure' (easy-normal-difficult) rated by the physician. This was filled in only 350 of 1711 cases. Available as SPSS file, by emailing the corresponding author.

Open Access This is an Open Access article distributed in accordance with the Creative Commons Attribution Non Commercial (CC BY-NC 4.0) license, which permits others to distribute, remix, adapt, build upon this work non-commercially, and license their derivative works on different terms, provided the original work is properly cited and the use is non-commercial. See: http://creativecommons.org/ licenses/by-nc/4.0/

\section{REFERENCES}

1 Quine MA, Bell GD, McCloy RF, et al. Prospective audit of upper gastrointestinal endoscopy in two regions of England: safety, staffing, and sedation methods. Gut 1995;36:462-7.

2 Sacchetti A, Senula G, Strickland J, et al. Procedural sedation in the community emergency department: initial results of the ProSCED registry. Acad Emerg Med 2007; $14: 41-6$

3 Tohda G, Higashi S, Wakahara S, et al. Propofol sedation during endoscopic procedures: safe and effective administration by registered nurses supervised by endoscopists. Endoscopy 2006;38:360-7.

4 Dutch institute for healthcare improvement (CBO). Richtlijn sedatie en of analgesie (PSA) op locaties buiten de operatiekamer Deel I: bij volwassenen. CBO 2012:1-128. http://www.diliguide.nl/document/3064

5 Thijssen WAMH, Giesen PHJ, Wensing M. Emergency departments in The Netherlands. Emerg Med J 2012;29:6-9.

6 Kuypers MI, Mencl F, Verhagen MF, et al. Safety and efficacy of procedural sedation with propofol in a country with a young emergency medicine training program. Eur J Emerg Med 2011;18:162-7.
7 Smith I, Kranke P, Murat I, et al. Perioperative fasting in adults and children: guidelines from the European Society of Anaesthesiology. Eur J Anaesthesiol 2011;28:556-69.

8 Dutch institute for healthcare improvement (CBO). Sedation and/or analgesia by non-anaesthesiologists. 1998. ISBN 9069102161.

9 Consales G, Chelazzi C, Rinaldi S, et al. Bispectral Index compared to Ramsay score for sedation monitoring in intensive care units. Minerva Anestesio/ 2006;72:329-36.

10 Bijur PE, Latimer CT, Gallagher EJ. Validation of a verbally administered numerical rating scale of acute pain for use in the emergency department. Acad Emerg Med 2003;10:390-2.

11 Mason KP, Green SM, Piacevoli Q. Adverse event reporting tool to standardize the reporting and tracking of adverse events during procedural sedation: a consensus document from the World SIVA International Sedation Task Force. Br J Anaesth 2012;108:13-20

12 Miner JR, Danahy M, Moch A, et al. Randomized clinical trial of etomidate versus propofol for procedural sedation in the emergency department. Ann Emerg Med 2007:49:15-22.

13 Jacques KG, Dewar A, Gray A, et al. Procedural sedation and analgesia in a large UK Emergency Department: factors associated with complications. Emerg Med J 2011;28:1036-40.

14 Reynolds JC, Abraham MK, Barrueto FF, et al. Propofol for procedural sedation and analgesia reduced dedicated emergency nursing time while maintaining safety in a community emergency department. J Emerg Nurs 2013;39:502-7.

15 Elkhodair SM, Baker EC, Glasebrook WR, et al. Emergency department procedural sedation: the London experience. Eur J Emerg Med 2015;22:407-12.

16 Newstead B, Bradburn S, Appelboam A, et al. Propofol for adult procedural sedation in a UK emergency department: safety profile in 1008 cases. $\mathrm{Br} J$ Anaesth 2013;111:651-5.

17 Miner JR, Moore JC, Austad EJ, et al. Randomized, double-blinded, clinical trial of propofol, 1:1 propofol/ketamine, and 4:1 propofol/ketamine for deep procedural sedation in the emergency department. Ann Emerg Med 2015;65:479-88.e2.

18 Heuss LT, Schnieper P, Drewe J, et al. Conscious sedation with propofol in elderly patients: a prospective evaluation. Aliment Pharmacol Ther 2003;17:1493-501.

19 Holdgate A, Taylor DM, Bell A, et al. Factors associated with failure to successfully complete a procedure during emergency department sedation. Emerg Med Australas 2011;23:474-8

20 Hohl CM, Sadatsafavi M, Nosyk B, et al. Safety and clinical effectiveness of midazolam versus propofol for procedural sedation in the emergency department: a systematic review. Acad Emerg Med 2008;15:1-8.

21 Deitch K, Chudnofsky CR, Dominici P. The utility of supplemental oxygen during emergency department procedural sedation and analgesia with midazolam and fentanyl: a randomized, controlled trial. Ann Emerg Med 2007;49:1-8.

22 Taylor DM, O'Brien D, Ritchie $P$, et al. Propofol versus midazolam/fentanyl for reduction of anterior shoulder dislocation. Acad Emerg Med 2005;12:13-19.

23 Rahman NHNA, Hashim A. The use of propofol for procedural sedation and analgesia in the emergency department: a comparison with midazolam. Emerg Med J 2011;28:861-5.

24 Swann A, Williams J, Fatovich DM. Recall after procedural sedation in the emergency department. Emerg Med J 2007;24:322-4. 